\title{
PALHADAS DE SORGO ASSOCIADAS AO HERBICIDA IMAZAMOX NO DESENVOLVIMENTO DA CULTURA DA SOJA EM SUCESSÃO(1)
}

\author{
Núbia Maria Correia ${ }^{(2)}$, Itamar Ferreira de Souza ${ }^{(3)}$ e Urubatan Palhares Klink ${ }^{(4)}$ \\ ${ }^{(1)}$ Parte da dissertação de mestrado do primeiro autor. \\ ${ }^{(2)}$ Eng $^{\text {a }}$. Agrônoma, Doutoranda do Curso de Produção Vegetal. Faculdade de Ciências Agrárias e Veterinárias/Universidade Estadual Paulista. \\ nubiamc@bol.com.br \\ ${ }^{(3)} \mathrm{Eng}^{\circ}$. Agrônomo, PhD, Professor. Departamento de Agricultura, Universidade Federal de Lavras. Caixa Postal 37. Lavras, MG 37200-000. \\ itamarfs@ufla.br \\ ${ }^{\left({ }^{4}\right)} \mathrm{Eng}^{\circ}$. Agrônomo, Doutor, Gerente de Pesquisa. Pesquisa e Desenvolvimento, Monsanto Sementes S.A. urubatan.p.klink@ monsanto.com
}

\section{RESUMO}

Com o objetivo de avaliar o efeito das palhadas dos híbridos de sorgo Saara, DK 860 e Ambar, associadas a três doses do herbicida imazamox (0,15 e $30 \mathrm{~g} / \mathrm{ha}$ ), no desenvolvimento da cultura da soja (cv. Conquista) cultivada em sucessão, foi conduzido no ano agrícola 2000/2001, um experimento de campo em Uberlândia, MG. As palhadas de sorgo cultivado no inverno não interferiram na altura final das plantas, na massa seca da parte aérea e no rendimento de grãos de soja. Embora tenha havido aumento de $11 \%$ no peso de 100 sementes, houve redução no número de nós da haste principal das plantas de soja cultivadas sobre as palhadas do DK 860 e Saara. O imazamox influiu negativamente em todas as variáveis avaliadas nas plantas de soja, ocorrendo inclusive redução de $8 \%$ no rendimento de grãos. As palhadas de sorgo e o herbicida imazamox comportaram-se como fatores independentes não apresentando efeito interativo entre eles.

Palavras-chave: alelopatia, Glycine max, semeadura direta, Sorghum bicolor.

\section{ABSTRACT \\ Effect of sorghum straw associated with imazamox herbicide on the development of the soybean crop planted in succession}

This experiment had the objective of evaluating the effects of grain sorghum, Saara, DK 860 and Ambar hybrids, associated with the imazamox herbicide, applied at 0,15 and $30 \mathrm{~g} / \mathrm{ha}$, on soybean (cv. Conquista) growth planted after sorghum desication. Sorghum straw did not affect soybean plant height, above ground dry matter and grain yield. Node number was reduced by DK 860 and Saara straw while these hybrids promoted $11 \%$ increase in 100 seed weight. Imazamox caused a decrease in the soybean evaluated parameters with a $8 \%$ grain yield reduction. Sorghum hybrids straws and the imazamox herbicide performed as independent factors with no interactive effects on soybean.

Key words: allelopathy, direct sowing, Glycine max, Sorghum bicolor. 


\section{INTRODUÇÃO}

O sorgo (Sorghum bicolor L.) mostra-se uma excelente alternativa como cultura de inverno, produzindo uma cobertura própria para o estabelecimento do sistema de semeadura direta no Cerrado, pois caracteriza-se por resistir melhor às condições de deficiência hídrica, com elevada capacidade de aproveitamento da água e conversão em biomassa seca (Santos, 1996).

O sorgo apresenta características alelopáticas verificadas principalmente pela exsudação de aleloquímicos através dos pêlos radiculares, compostos estes que também se encontram presentes nas sementes, raízes, colmos e folhas em quantidade variáveis (Peixoto, 1999), interferindo no manejo das plantas cultivadas e daninhas (Santos, 1996).

Estas substâncias orgânicas, os aleloquímicos, são citadas como causadores de uma grande diversidade de efeitos nas plantas. Esses efeitos incluem o atraso ou a inibição completa da germinação de sementes, paralisação do crescimento, injúria no sistema radicular, clorose, murcha e morte das plantas. O potencial alelopático de uma espécie depende do genótipo, do seu estádio de desenvolvimento e das condições ambientais, como a intensidade luminosa e variações de estresse (Rice, 1984).

Através de bioensaios pode-se detectar rapidamente diferenças no potencial alelopático de híbridos de sorgo. Uma vez determinada a potencialidade alelopática de um genótipo, os resultados poderão ser confirmados em campo, auxiliando na escolha do genótipo mais adequado para a sucessão sorgo (inverno) e a cultura subseqüente (verão).

Várias pesquisas têm sido realizadas visando o manejo dos resíduos vegetais no desenvolvimento das culturas em sucessão. Roth et al. (2000) constataram que a palhada de sorgo, híbrido Taylor Evans Y-101G, quando incorporada ao solo retardou o desenvolvimento do trigo em sucessão, porém não afetou o rendimento de grãos da cultura. Os resíduos vegetais de sorgo mantidos na superfície do solo, sem incorporação, apesar de pouco afetarem o estande do trigo, reduziram o rendimento de grãos. Em outro trabalho desenvolvido por Ben-Hammouda et al. (1995) foi observado que as folhas, os colmos e as raízes de sorgo apresentaram maior atividade alelopática sobre plântulas de trigo, reduzindo-se o alongamento das radículas em até $74,7 \%$ pelos colmos. Entre os seis híbridos de sorgo estudados, o Taylor Evans Y-101G foi o mais alelopático, e os genótipos Asgrow Topaz e Warner W744DR apresentaram menor potencial alelopático.

No entanto, a palhada de sorgo assume também um importante papel no manejo integrado das plantas daninhas (Einhellig \& Rasmussen, 1989; Pereira, 1990; Hoffman et al., 1996; Pasqualetto, 1999), contribuindo para o controle e permitindo, em alguns casos, minimizar o uso de herbicidas com redução de doses. Faz-se necessário o estudo dos resíduos vegetais de sorgo associados à redução de doses de herbicidas, como alternativa no controle das plantas daninhas no sistema de semeadura direta, e conseqüentemente o efeito desta prática na cultura de verão.
Entre os principais herbicidas registrados para as culturas da soja e do feijão, destaca-se o imazamox, que apresenta um amplo espectro de controle de espécies de folhas largas (Cyanamid Química do Brasil, 1997). Pertence ao grupo químico das imidazolinonas, sendo um potente inibidor da enzima acetolactato sintase (ALS). A enzima ALS, presente predominantemente nos tecidos jovens das plantas, regula preliminarmente duas rotas metabólicas que darão origem aos aminoácidos de cadeia ramificada valina, leucina e isoleucina (Leite et al., 1998).

Este trabalho teve como objetivo avaliar, em condições de campo, o efeito das palhadas de híbridos de sorgo, cultivados no inverno, associadas ao uso do herbicida imazamox, no desenvolvimento da cultura da soja em sucessão ao sorgo, sob semeadura direta.

\section{MATERIAL E MÉTODOS}

O experimento foi conduzido no período de março de 2000 a março de 2001, em condições de campo, no Centro de Pesquisa Milho e Sorgo Monsanto, localizado na BR 452, km 154, em Uberlândia, MG.

O delineamento experimental utilizado foi o de blocos ao acaso com quatro repetições, em esquema de parcela subdividida com quatro tipos de palhada na parcela, sendo três provenientes de resíduos culturais de híbridos de sorgo (Saara, DK 860 e Ambar) e uma sem restos vegetais de sorgo (pousio invernal), e três doses de imazamox na subparcela: sem herbicida ( $0 \mathrm{~g} / \mathrm{ha})$, metade da dose recomendada ( $15 \mathrm{~g} / \mathrm{ha})$ e dose recomendada (30 g/ha).

\section{Cultura do sorgo}

O sorgo foi semeado no dia 20 de março de 2000 , sob palhada de soja e de plantas daninhas, em sistema de semeadura direta. Após a semeadura foi realizada a aplicação da mistura dos herbicidas atrazine $(1,5 \mathrm{~kg} / \mathrm{ha})$ e paraquat $(0,3 \mathrm{~kg} /$ ha).

As parcelas foram constituídas por seis linhas espaçadas de $0,5 \mathrm{~m}$, com 15 metros de comprimento e densidade de 12 plantas por metro, perfazendo uma população de 240 mil plantas/ha.

Foi determinada, cinco dias antes da colheita dos grãos, a massa seca da parte aérea (kg/ha) por híbrido de sorgo. Em cada parcela foram delimitados quatro pontos de amostragem, escolhidos aleatoriamente, com $10 \mathrm{~m}^{2}$ cada, sendo em cada ponto coletadas 12 plantas, as quais tiveram as sementes eliminadas. Em seguida as plantas foram picadas e levadas para secar a $62^{\circ} \mathrm{C}$, em estufa de circulação forçada de ar, até atingirem peso constante. Não foi realizada análise estatística destes resultados, sendo utilizados apenas para complementar ou justificar possíveis informações obtidas na cultura da soja. 
Os grãos foram colhidos 156 dias após a emergência das plântulas. Após a colheita dos grãos, as plantas foram trituradas utilizando-se um cortador de palha da marca Triton e deixadas sobre as parcelas.

Trinta e seis dias após a trituração das plantas fez-se a dessecação química das plantas daninhas e da rebrota do sorgo, quando estas encontravam-se com $20 \mathrm{~cm}$ de altura. Utilizouse, para isto, o herbicida glyphosate na dose de $1,8 \mathrm{~kg} / \mathrm{ha}$ i.a.

\section{Cultura da soja}

Antecedendo a semeadura da soja fez-se, para cada parcela, uma análise de solo, cujos resultados podem ser observados na Tabela 1. De acordo com Novais (1999) e baseando-se nos resultados das análises de solo e na necessidade nutricional da soja, fez-se a recomendação de adubação, que foi geral para todas as parcelas. Foram aplicados $329 \mathrm{~kg} / \mathrm{ha} \mathrm{do}$ formulado 02-20-20 no sulco de semeadura.

A soja foi semeada um mês após a dessecação da rebrota das plantas de sorgo, no dia 1 de novembro de 2001, em sistema de semeadura direta, à profundidade de $5 \mathrm{~cm}$, com $0,5 \mathrm{~m}$ de distância entre as linhas e 20 sementes por metro, perfazendo uma população de $400 \mathrm{mil}$ plantas/ha. A cultivar utilizada foi a Conquista. As sementes de soja foram tratadas com carboxin (1,5 g/kg de sementes) e inoculadas com 7,5 g/ $\mathrm{kg}$ do inoculante marca Leiva.

Dentro das parcelas foram demarcadas subparcelas correspondentes às doses de imazamox $(0,15$ e $30 \mathrm{~g} / \mathrm{ha})$. As subparcelas foram constituídas por seis linhas de soja com cinco metros de comprimento, considerando-se quatro linhas centrais de quatro metros como área útil, totalizando $8 \mathrm{~m}^{2}$.

Todas as subparcelas, incluindo as que receberam ou não o herbicida, foram capinadas semanalmente, desde a aplicação do imazamox até o total fechamento da cultura, de modo que os efeitos das palhadas ou do herbicida não fossem mascarados pela interferência das plantas daninhas.

O herbicida imazamox foi aplicado em pós-emergência precoce das plantas daninhas quando estas encontravam-se com dois pares de folhas definitivas e as plantas de soja estavam com o segundo trifólio totalmente expandido. Utilizou-se um pulverizador costal, à pressão constante de $2,8 \mathrm{~kg} / \mathrm{cm}^{2}$, munido de uma barra com quatro bicos de jato plano ("leque") uniforme $8002 \mathrm{EVS}$, espaçados de $0,5 \mathrm{~m}$ e com consumo de calda equivalente a $200 \mathrm{~L} / \mathrm{ha}$.

Foram realizadas avaliações visuais dos sintomas de intoxicação nas plantas de soja aos 10 e 24 dias após a aplica- ção (DAA) do herbicida, atribuindo-se, a cada unidade experimental, uma nota média de dois avaliadores, em percentagem. Adotou-se 0 para nenhuma injúria e $100 \%$ como morte da planta. Determinou-se a altura $(\mathrm{cm})$ das plantas de soja, considerando-se a distância entre o colo da planta e a extremidade da haste principal. Estas avaliações foram feitas aos 10, 24 e 64 DAA. Aos 64 DAA, fez-se também a contagem do número de nós da haste principal e a determinação da massa seca da parte aérea das plantas (g/planta). Estes valores foram tomados a partir de dez plantas coletadas ao acaso na área útil da unidade experimental. Para a obtenção da produção de grãos foram colhidas manualmente quatro linhas de quatro metros de comprimento, sendo posteriormente trilhadas, sendo essa corrigida para a umidade de grãos de 13,5\%. Determinou-se, também, o peso (g) de 100 sementes.

Os resultados obtidos foram submetidos ao teste $\mathrm{F}$ para análise de variância, e os efeitos das palhadas e do herbicida imazamox foram comparados pelo teste de Tukey ao nível de 5\% de probabilidade. O programa estatístico utilizado foi o SISVAR (Ferreira, 2000).

\section{RESULTADOS E DISCUSSÃO}

A interação palhadas $x$ doses de imazamox não foi significativa para nenhuma característica avaliada nas plantas de soja, mostrando que os fatores comportaram-se de forma independente (Tabelas 2 e 3 ).

Houve efeito significativo das palhadas na altura das plantas de soja aos 10 e 24 DAA. As doses do herbicida proporcionaram diferença na altura das plantas apenas na última época de avaliação aos 64 DAA (Tabela 2). Nessa ocasião, as doses de imazamox influenciaram no número de nós, na massa seca da parte aérea, no peso de 100 sementes e no rendimento de grãos; as palhadas diferiram apenas quanto ao número de nós e peso de 100 sementes (Tabela 3).

Não se observaram, visualmente, sintomas de intoxicação proporcionados pelas palhadas de sorgo e pelo herbicida nas plantas de soja aos 10 e 24 DAA. O mesmo não ocorreu em trabalho similar realizado por Peixoto (1999), que constatou clorose internerval nas plantas de soja (cv. Garimpo), de forma mais acentuada nas doses de $20 \mathrm{e} 30 \mathrm{~g} / \mathrm{ha}$ do herbicida imazamox. O autor mencionou, ainda, que os sintomas da intoxicação ocasionadas pelos resíduos de sorgo foram caracteri-

Tabela 1. Resultados da análise de solo ${ }^{1}$ realizada antes da semeadura da soja. Uberlândia, MG.2000/2001.

\begin{tabular}{|c|c|c|c|c|c|c|c|c|}
\hline \multirow[t]{2}{*}{ Parcelas } & \multirow{2}{*}{$\begin{array}{l}\text { pHágua } \\
(1: 2,5)\end{array}$} & $\mathbf{P}$ & $\mathbf{K}$ & $\mathrm{Ca}$ & $\mathbf{M g}$ & $\overline{A l}$ & $\mathbf{V}$ & MO \\
\hline & & \multicolumn{2}{|c|}{$\ldots . . . . . m g / \mathrm{dm}^{3} . . . .}$. & \multicolumn{3}{|c|}{.................cmol $/ \mathrm{dm}^{3}$...................... \% } & \multicolumn{2}{|c|}{$\mathrm{dag} / \mathrm{kg}$} \\
\hline Saara & 6,3 & 6,0 & 97,0 & 3,3 & 1,1 & - & 64,1 & 3,3 \\
\hline DK 860 & 6,3 & 9,0 & 72,0 & 3,3 & 1,9 & 0,1 & 70,1 & 3,6 \\
\hline Ambar & 6,6 & 7,0 & 58,0 & 3,7 & 1,8 & - & 76,9 & 3,1 \\
\hline Pousio & 5,9 & 8,0 & 90,0 & 3,5 & 1,0 & 0,1 & 69,3 & 3,5 \\
\hline
\end{tabular}

${ }^{1}$ Laboratório de Análises de Solo do Departamento de Ciência do Solo/UFLA. Lavras, MG. 
Núbia Maria Correia et. al.

Tabela 2. Resumo da análise de variância da altura $(\mathrm{cm})$ das plantas de soja, nas três épocas de avaliação, em função das palhadas e das doses do herbicida imazamox. Uberlândia, MG. 2000/2001.

\begin{tabular}{lcccc}
\hline \multirow{2}{*}{ Fontes de Variação } & GL & & Quadrado Médio & 64 DAA \\
\cline { 3 - 5 } & & $\mathbf{1 0 ~ D A A}^{(\mathbf{1})}$ & 24 DAA & 1,7222 \\
\hline Bloco & 3 & 0,1947 & $57,8529 * *$ & 115,1852 \\
Palhada (P) & 3 & $9,5547^{* *}$ & 3,7041 & 84,3253 \\
Resíduo (a) & 9 & 0,5331 & 18,7020 & $316,4457 * *$ \\
Doses (D) & 2 & 2,3819 & 4,7350 & 150,9381 \\
Interação (PxD) & 6 & 0,8799 & 5,0816 & 20,1226 \\
Resíduo (b) & 24 & 2,2368 & 6,27 & 12,11 \\
C.V.1(\%) & & 4,91 & 7,35 & 5,91 \\
C.V. $2(\%)$ & & 10,06 & & \\
\hline
\end{tabular}

(1)DAA = dias após a aplicação do imazamox.

**Significativo pelo teste $\mathrm{F}$ ao nível de $1 \%$ de probabilidade.

Tabela 3. Resumo da análise de variância do número de nós por planta (NN), massa seca da parte aérea (MSPA), peso de 100 sementes (P100) e rendimento de grãos (RG) de soja, em função das palhadas e das doses do herbicida imazamox. Uberlândia, MG. 2000/2001.

\begin{tabular}{lclccc}
\hline & & \multicolumn{4}{c}{ QuadradoMédio } \\
\cline { 3 - 5 } Fontes de Variação & GL & NN & $\begin{array}{c}\text { MSPA } \\
\text { (g/planta) }\end{array}$ & P100 & RG \\
\hline Bloco & 3 & $2,3431^{*}$ & 29,4710 & 0,2003 & 30,974 \\
Palhada (P) & 3 & $4,6075^{* *}$ & 16,2737 & $14,7473^{* *}$ & 52707 \\
Resíduo (a) & 9 & 0,3194 & 25,3619 & 1,0859 & 16249 \\
Doses (D) & 2 & $5,7025^{*}$ & $81,9763 *$ & $3,3019 *$ & $288050^{*}$ \\
Interação (PxD) & 6 & 1,2358 & 24,8861 & 0,5626 & 14131 \\
Resíduo (b) & 24 & 0,8269 & 16,3853 & 0,7842 & 62761 \\
C.V.1(\%) & & 5,72 & 21,91 & 5,27 & 4,82 \\
C.V.2(\%) & & 9,20 & 17,91 & 4,48 & 9,47 \\
\hline
\end{tabular}

**, * Significativo pelo teste $\mathrm{F}$ ao nível de $1 \%$ e $5 \%$ de probabilidade, respectivamente.

zados por uma clorose foliar que permaneceu por um período mais prolongado que o sintoma provocado pelas doses de imazamox.

A aplicação de imazamox após a emissão do segundo trifólio pelas plantas de soja poderá provocar uma redução na altura das plantas ou resultar em uma clorose passageira (Cyanamid Química do Brasil, 1997).

Observando-se o efeito das palhadas sobre a altura das plantas de soja aos 10 e 24 DAA (Tabela 4), constatou-se que, na palhada do híbrido DK 860, as plantas apresentaram maior altura, a qual, entretanto, não diferiu da palhada do pousio. Na avaliação aos $64 \mathrm{DAA}$, não houve diferença significativa entre as palhadas. Pasqualetto (1999) também observou que a palhada de sorgo, quando comparada aos resíduos culturais de girassol, milho, milheto, soja, nabo forrageiro e aveia, não afetou a altura das plantas de soja em sucessão. No entanto, Peixoto (1999) mencionou que a palhada de sorgo interferiu na altura das plantas de soja, desde as fases iniciais até a fase de pré-colheita (90 DAA).
As plantas desenvolvidas sob as palhadas do Ambar e do pousio apresentaram maior número de nós da haste principal. Já as palhadas dos híbridos DK 860 e Saara proporcionaram um aumento de $11 \%$ no peso de 100 sementes. No entanto, embora tenha havido diferença significativa entre as palhadas para esta características, não houve efeito das mesmas no rendimento de grãos (Tabela 5)

Conforme Sediyama et al. (1985), existe uma correlação positiva entre a altura das plantas de soja e o rendimento de grãos. No presente estudo, constatou-se que não houve diferença significativa entre as palhadas na altura final das plantas de soja e, também, no rendimento de grãos.

Pasqualetto (1999) mencionou que não houve diferença significativa entre a palhada de sorgo e os demais resíduos culturais estudados quanto ao peso de 100 sementes e rendimento de grãos de soja. $\mathrm{O}$ autor verificou também que as plantas de soja em sucessão ao sorgo apresentaram maior acúmulo de biomassa seca. No trabalho conduzido por Peixoto (1999), os resíduos vegetais de sorgo afetaram o rendimento de grãos 
Tabela 4. Altura (cm) das plantas de soja, aos 10, 24 e 64 dias após a aplicação (DAA) do imazamox, submetidas a palhadas de híbridos de sorgo. Uberlândia, MG. 2000/2001.

\begin{tabular}{lccr}
\hline \multirow{2}{*}{ Fontes de Variação } & \multicolumn{3}{c}{ Épocas de avaliação } \\
& 10 DAA & 24 DAA & 64 DAA \\
\hline Saara & $14,51 \mathrm{bc}^{(2)}$ & $29,37 \mathrm{bc}$ & $75,82 \mathrm{a}$ \\
DK860 & $15,80 \mathrm{a}$ & $33,25 \mathrm{a}$ & $80,23 \mathrm{a}$ \\
Ambar & $13,79 \mathrm{c}$ & $28,43 \mathrm{c}$ & $74,10 \mathrm{a}$ \\
Pousio & $15,35 \mathrm{ab}$ & $31,71 \mathrm{ab}$ & $73,29 \mathrm{a}$ \\
\hline
\end{tabular}

${ }^{(2)}$ Em cada coluna, médias seguidas pelas mesmas letras não diferem, significativamente entre si, pelo teste de Tukey a 5\% de probabili dade.

de soja, havendo decréscimo no rendimento de grãos com o aumento populacional (0,100 mil, $200 \mathrm{mil} \mathrm{e} 300 \mathrm{mil} \mathrm{plantas} / \mathrm{ha})$ do sorgo (cv. BR303), dessecado aos 60 dias após a emergência. $\mathrm{O}$ autor, entretanto, não relatou a quantidade de resíduos remanescentes no solo após a dessecação das plantas.

Neste estudo, constatou-se que o híbrido Ambar produziu $5430 \mathrm{~kg} / \mathrm{h}$ a de massa seca, o DK $860,5425 \mathrm{~kg} / \mathrm{ha}$, e o Saara, $5045 \mathrm{~kg} / \mathrm{ha}$, mostrando que a quantidade de resíduos vegetais mantidos na superfície do solo foi quase a mesma para os três híbridos.

Deve ser levado em consideração que a adição de material vegetal com alta relação $\mathrm{C} / \mathrm{N}$ ao solo, como a palhada de sorgo, resulta em maior atividade microbiana, que condiciona uma imobilização do nitrogênio e fósforo do solo. Assim, qualquer resposta de crescimento após a adição de resíduos culturais pode ser devido ao esgotamento do nitrogênio e fósforo do solo, e não às moléculas orgânicas, como afirmam Inderjit \& Keating (1999). De acordo com Pasqualetto (1999), a deficiência de fósforo, além do empobrecimento do sistema radicular, ocasiona interferência no desenvolvimento da parte aérea das plantas de soja. Quanto ao nitrogênio, a sua imobilização interfere no estabelecimento inicial da cultura da soja, com conseqüências futuras no seu porte.

Com relação ao efeito das doses do imazamox na altura das plantas de soja (Tabela 6), observou-se que aos 10 e 24 DAA não houve diferença entre as doses. Aos 64 DAA verificou-se decréscimo na altura das plantas com o aumento da dose do herbicida, alcançando diferença de $10,6 \%$ entre os tratamentos sem herbicida e dose recomendada.

O número de nós, a massa seca da parte aérea, o peso de 100 sementes e o rendimento de grãos foram influenciados com a aplicação do herbicida. (Tabela 7). Observou-se uma diferença de $9,8 \%$ no número de nós entre os tratamentos sem e com imazamox. Para a produção de massa seca, peso de 100 sementes e rendimento de grãos, estas diferenças foram de $13,2 \%, 2,9 \%$ e 8,3\%, respectivamente. Vários autores (Duarte et al., 1997; Nelson \& Renner,1998; Melo et al., 2001) também verificaram efeitos negativos do herbicida imazamox nas características de produção da soja.
Tabela 5. Número de nós por planta (NN), massa seca da parte áerea (MSPA), peso de 100 sementes (P100) e rendimento de grãos (RG) de soja, submetida a palhadas de sorgo. Uberlândia, MG. 2000/2001.

\begin{tabular}{lcccr}
\hline Palhadas & NN & $\begin{array}{c}\text { MSPA } \\
(\mathrm{g} / \text { planta }\end{array}$ & $\begin{array}{c}\text { P100 } \\
(\mathrm{g})\end{array}$ & $\begin{array}{c}\text { RG } \\
(\mathrm{kg} / \mathrm{ha})\end{array}$ \\
\hline Saara & $9,23^{(1)}$ & $22,03 \mathrm{a}$ & $20,71 \mathrm{a}$ & $2704,77 \mathrm{a}$ \\
DK 860 & $9,50 \mathrm{~b}$ & $22,56 \mathrm{a}$ & $20,65 \mathrm{ab}$ & $2640,82 \mathrm{a}$ \\
Ambar & $10,28 \mathrm{a}$ & $22,67 \mathrm{a}$ & $19,35 \mathrm{bc}$ & $2581,99 \mathrm{a}$ \\
Pousio & $1053 \mathrm{a}$ & $24,68 \mathrm{a}$ & $18,40 \mathrm{c}$ & $2658,94 \mathrm{a}$ \\
\hline
\end{tabular}

(1) Em cada coluna, médias seguidas pelas mesmas letras não diferem, significativamente entre si, pelo teste de Tukey a 5\% de probabilidade.

A graduação do efeito tóxico do imazamox em plantas de soja pode ser explicado pela capacidade diferenciada de cada genótipo em absorver, translocar e metabolizar o herbicida a uma forma menos ativa ou totalmente inativa. A detoxificação

Tabela 6. Altura (cm) das plantas de soja, aos 10, 24 e 64 dias após a aplicação (DAA) de três doses de herbicida imazamox. Uberlândia, MG. 2000/2001.

\begin{tabular}{lccc}
\hline \multirow{2}{*}{$\begin{array}{l}\text { Herbicida } \\
\text { (Doses) }\end{array}$} & \multicolumn{3}{c}{ Épocas de avaliação } \\
\cline { 2 - 4 } $\mathrm{SH}^{(1)}$ & 10 DAA & 24 DAA & 64 DAA \\
$\mathrm{MDR}$ & $15,18 \mathrm{a}^{(2)}$ & $31,93 \mathrm{a}$ & $80,81 \mathrm{a}$ \\
$\mathrm{DR}$ & $14,43 \mathrm{a}$ & $30,20 \mathrm{a}$ & $74,56 \mathrm{ab}$ \\
\hline
\end{tabular}

(1) SH - sem herbicida, MDR - metade da dose recomendada, DR dose recomendada.

(2) Em cada coluna, médias seguidas pelas mesmas letras não diferem, significativamente entre si, pelo teste de Tukey a $5 \%$ de probabilidade.

Tabela 7. Número de nós por planta (NN), massa seca da parte áerea (MSPA), peso de 100 sementes (P100) e rendimento de grãos (RG) de soja, submetida a três doses do herbicida imazamox. Uberlândia, MG. 2000/ 2001.

\begin{tabular}{lcccc}
\hline $\begin{array}{l}\text { Herbicida } \\
\text { (Doses) }\end{array}$ & NN & $\begin{array}{c}\text { MSPA } \\
(\mathrm{g} / \text { planta }\end{array}$ & $\begin{array}{c}\text { P100 } \\
(\mathrm{g})\end{array}$ & $\begin{array}{c}\text { RG } \\
(\mathrm{kg} / \mathrm{ha})\end{array}$ \\
\hline $\mathrm{SH}^{(1)}$ & $10,58 \mathrm{a}^{(2)}$ & $25,19 \mathrm{a}$ & $20,17 \mathrm{a}$ & $2800,77 \mathrm{a}$ \\
MDR & $9,59 \mathrm{~b}$ & $23,08 \mathrm{ab}$ & $19,89 \mathrm{ab}$ & $2583,15 \mathrm{ba}$ \\
\hline
\end{tabular}

${ }^{(1)} \mathrm{SH}=$ sem herbicidas, $\mathrm{MDR}=$ metade da dose recomendada, $\mathrm{DR}=$ dose recomendada.

${ }^{(2)}$ Em cada coluna, médias seguidas pelas mesmas letras na mesma coluna não diferem, signicativamente entre si, pelo teste de Tukey a $5 \%$ de probabilidade.

do imazamox ocorre pela hidroxilação do seu grupo alquil, formando o metabólito análogo (5-hidroximetil), ambos tendo atividade herbicida, porém este último posteriormente sofre conjugação com glicose, passando a inativo na soja (Hess \& Anderson, 1995). 


\section{CONCLUSÕES}

As palhadas de sorgo cultivado no inverno, embora tenham proporcionado alturas diferentes das plantas de soja até 24 DAA, não interferiram na altura final das plantas, na massa seca da parte aérea e no rendimento de grãos de soja.

O imazamox, mesmo na metade da dose recomendada, influiu negativamente na altura final das plantas, no número de nós da haste principal, na massa seca da parte aérea, no peso de 100 sementes e no rendimento de grãos de soja.

As palhadas de sorgo e o herbicida imazamox comportaram-se como fatores independentes, não apresentando efeito interativo entre eles.

\section{LITERATURA CITADA}

BEN-HAMMOUDA, M.; KREMER, R.J.; MINOR, H.C. Phytotoxicity of extracts from sorghum plant components on wheat seedlings. Crop Science, v. 35, n. 6, p. 1652$1656,1995$.

CYANAMID QUIIMICA DO BRASIL. Raptor $^{\circledR}$ 70 DG, 1997. 15 p. (Boletim Técnico)

DUARTE, N. de F.; SILVA, J.B. da; ARCHANGELO, E.R.; OLIVEIRA, J.R. de. Avaliação de imazethapyr e imazamox no controle pós-emergente de plantas daninhas na cultura da soja. In: CONGRESSO BRASILEIRO DA CIÊNCIA DAS PLANTAS DANINHAS, 21. Caxambu, 1997. Resumos... Viçosa: SBCPD, 1997. p. 77.

EINHELLIG, F. A.; RASMUSSEN, J. A. Prior cropping with grain sorghum inhibits weeds. Journal of Chemical Ecology, v. 15, n. 3, p. 951-960, 1989.

FERREIRA, D.F. Análises estatísticas por meio do SISVAR para Windows versão 4.0. In: REUNIÃO ANUAL DA REGIÃO BRASILEIRA DA SOCIEDADEINTERNACIONAL DE BIOMETRIA, 45. São Carlos, SP, 2000. Programa e Resumos... São Carlos: UFSCar, 2000. p. 235.

HESS, F.D.; ANDERSON, R. Herbicides in development in the U.S. In: Herbicide action course. West Lafayette: Purdue University, 1995.p. 407.

HOFFMAN, M. L.; WESTON, L. A.; SNYDER, J. C.; REGNIER, E. E. Separating the effects of sorghum (Sorghum bicolor) and rye (Secale cereale) root and shoot residues on weed development. Weed Science, v. 44, p. 402-407, 1996.

INDERJIT; KEATING, K.I. Allelopathy: Principles, procedures, processes, and promises for biological control. Advances in Agronomy, v. 67, p. 141-231, 1999.
LEITE, C.R.F.; ALMEIDA, J.C.V. de; PRETE, C.E.C. Aspectos fisiológicos, bioquímicos e agronômicos das herbicidas inibidores da enzima ALS (AHAS). Londrina, PR, 1998. $68 \mathrm{p}$.

MELO, H.B.; FERREIRA, L.R.; SILVA, A.A.; MIRANDA, G.V.; ROCHA, V.S.; SILVA, C.M.M. Efeitos de espaçamentos entre linhas, épocas de aplicação e doses de imazamox no manejo de plantas daninhas na cultura da soja. Planta Daninha, v. 19, n. 2, p. 229-234, 2001.

NELSON, K.A.; RENNER, K.A. Weed control in wide - and narrow - row soybean (Glycine max) with imazamox, imazethapyr, and CGA - 277476 plus quizalofop. Weed Technology, v. 12, p. 137-144, 1998.

NOVAIS, R.F. de. Soja. In: RIBEIRO, A.C.; GUIMARÃES, P.T.G.; ALVAREZ, V.H. (Ed.). Recomendações para o uso de corretivos e fertilizantes em Minas Gerais. $5^{\underline{a}}$ aproximação. Viçosa: UFV, 1999.p. 323-324.

PASQUALETTO, A. Sucessão de culturas como alternativa de produção em plantio direto no cerrado. Viçosa: Universidade Federal de Viçosa, 1999. (Dissertação de Doutorado).

PEIXOTO, M.F. Resíduos de sorgo e doses de imazamox no controle de plantas daninhas na soja sob plantio direto. Lavras: Universidade Federal de Lavras, 1999. (Dissertação de Mestrado)

PEREIRA, F. A. R. Cultivo de espécies visando a obtenção de cobertura vegetal do solo na entressafra da soja (Glycine max L. Merril) no cerrado. Botucatu: Faculdade de Ciências Agronômicas/Universidade Estadual Paulista, 1990. (Dissertação de Mestrado).

RICE, E. L. Allelopathy. 2 ed. Orlando: Academic Press, 1984. $422 \mathrm{p}$.

ROTH, C.M.; SHROYER, J. P.; PAULSEN, G. M. Allelopathy of sorghum on wheat under several tillage systems. Agronomy Journal, v. 92, n. 5, p. 855-860, 2000.

SANTOS, O.G. Alelopatia de genótipos de sorgo (Sorghum bicolor) em sistemas de cultivos de hortaliças. Brasília: Universidade de Brasília, 1996. (Dissertação de Mestrado).

SEDIYAMA, T.; PEREIRA, M.G.; SEDIYAMA, C.S. Cultura da soja: Parte I. Viçosa: UFV, 1985.96 p. 